\title{
A TECNOLOGIA EM FAVOR DA DEMOCRACIA E DO MEIO AMBIENTE: O DIREITO À INFORMAÇÃO COMO PRIMEIRA CONDIÇÃO PARA TAL POSSIBILIDADE
}

\section{TECHNOLOGY IN FAVOUR OF DEMOCRACY AND THE ENVIRONMENT: THE RIGHT TO INFORMATION AS FIRST CONDITION FOR SUCH POSSIBILITY}

\author{
${ }^{1}$ Matheus Silva De Gregori \\ ${ }^{2}$ Patrícia Adriani Hoch
}

\section{RESUMO}

Este artigo visa analisar de que forma a tecnologia pode favorecer o exercício da democracia e o meio ambiente, especialmente considerando o direito à informação como primeira condição para tal possibilidade. Para tanto, utilizou-se o método de abordagem dedutivo aliado ao método de procedimento monográfico ou de estudo de casos, a partir do qual foram analisados casos relacionados ao direito à informação em matéria ambiental. Constatou-se que a informação ambiental, efetivamente, constitui-se como um requisito essencial para resgatar os indivíduos e coletivos para a promoção da cidadania e participação nos processos decisórios, visando o fortalecimento do Estado Democrático de Direito.

Palavras-chave: Democracia, Informação, Meio ambiente, Tecnologia

\begin{abstract}
This article aims to analyze how technology can facilitate the exercise of democracy and the environment, especially considering the right to information as a first condition for such a possibility. For this, we used the deductive method of approach coupled with the method of monographic procedure or case studies, from which were analyzed cases related to the right to environmental information. It was found that environmental information effectively constitutes an essential requirement to rescue individuals and groups to promote citizenship and participation in decision making, aimed at strengthening the democratic rule of law.
\end{abstract}

Keywords: Democracy, Environment, Information, Technology

\footnotetext{
${ }^{1}$ Mestrando do Programa de Pós-Graduação em Direito da Universidade Federal de Santa Maria -UFSM, Rio Grande do Sul, Brasil. Linha de Pesquisa: Direitos da Sociobiodiversidade e Sustentabilidade. Bolsista CAPES. E-mail: matheusdegre@gmail.com

${ }^{2}$ Mestranda do Programa de Pós-Graduação em Direito da Universidade Federal de Santa Maria -UFSM, Rio Grande do Sul, Brasil. Linha de Pesquisa: Direitos na Sociedade em Rede. Bolsista CAPES. E-mail: patricia.adriani@hotmail.com
} 


\section{INTRODUÇÃO}

A revolução tecnológica, aliada ao surgimento da sociedade informacional, em meados dos anos 70, trouxe diversos impactos para a vida em sociedade, especialmente ao proporcionar imediatismo, velocidade e aceleração da transmissão de informações, em nível global. A comunicação, interação e acesso ao conhecimento, através das tecnologias de informação e de comunicação (TIC'S), são realizados de forma interplanetária, descentralizada e libertária por meio da sofisticação da publicação e disseminação de conteúdos.

Ao trazer tais benefícios para a sociedade, as novas tecnologias constituíram-se como importantes instrumentos para favorecer o acesso à informação pela população, direito esse que possui caráter individual e coletivo e configura-se como essencial à participação cidadã, ao combate à corrupção e à realização de outros direitos socioeconômicos, políticos e civis. Isso, pois, os fluxos informacionais das novas tecnologias, com ênfase para a Internet, se destacam por apresentar mecanismos que permitem imensa circulação, tratamento e armazenamento de dados e informações, fomentando a comunicação, a interatividade e a aproximação dos usuários.

Nesse contexto, vislumbra-se a possibilidade de fortalecimento da democracia, uma vez que conhecimento e assimilação das informações pelos cidadãos permitem (ao menos idealmente), maior participação popular e exercício do controle social. Para tanto, as mídias digitais possuem inequívoco potencial de resgatar os ideais de associação, participação e de cooperação social, o que possui relação direta com o direito à informação, considerando que uma sociedade bem informada possui, evidentemente, maior e melhor capacidade para exercer a democracia.

Diante disso, o presente artigo visa responder o seguinte problema de pesquisa: de que forma a tecnologia pode favorecer o exercício da democracia, sobretudo nas problemáticas ambientais, considerando, neste sentido, o direito à informação como primeira condição para tal possibilidade?

Para tanto, utilizou-se o método de abordagem dedutivo, partindo-se da premissa de que se a tecnologia pode servir à promoção da democracia e da proteção ambiental, o "primeiro passo" é o acesso à informação, para participação social e politização das tecnologias, e como possibilidade de desenvolvimentos sustentável e articulação de redes e movimentos ambientalistas. Aliou-se, ainda, o método de procedimento monográfico ou de 
estudo de casos, através do qual foram analisados casos brasileiros exemplificativos envolvendo o direito de acesso à informação em matéria ambiental.

Para a fluidez da compreensão, o presente estudo foi dividido em dois tópicos. Em um primeiro momento, analisam-se os desafios trazidos pelas novas tecnologias, bem como suas relações com a democracia e necessidade de gerir a crise ambiental. Já na segunda parte, abordase o advento da categoria "Informação ambiental", como uma espécie do gênero "Direito à Informação", e sua importância para a participação da população em processos decisórios, passando-se finalmente a alguns exemplos brasileiros que envolvem a temática.

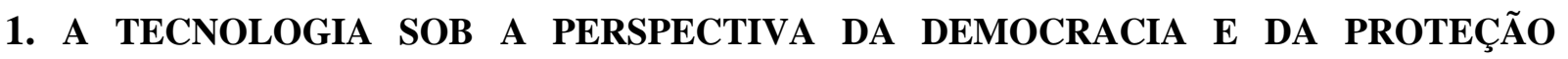 AMBIENTAL}

Cada nova invenção tecnológica, principalmente no âmbito da comunicação e informação, é louvada e legitimada, graças a seus avanços e possibilidades infinitas. A tecnologia é dotada de uma "auréola mágica e determinista", assumindo uma força apelativa maior que a razão e a moral, de modo que "a razão técnica teria sua lógica própria e um poder sem limites” (DUPAS, 2001, p. 60). Opiniões cautelosas, como afirma Dupas (2001, p. 61), “com relação a alimentos transgênicos, objeções éticas quanto aos imensos riscos da manipulação genética e reações contra o desemprego gerado pela automação radical, tudo é encarado como posição reacionária de quem não quer o progresso". O desenvolvimentismo, na acepção da racionalidade meramente econômica, casa-se perfeitamente com a ambição do avanço tecnológico irrestrito, de modo que a ciência assume um compromisso inabalável com o mercado, servindo antes a este, do que qualquer outro valor humano que se interponha caminho. Na visão de Arendt (2010, p.405-406), a ação dos cientistas,

\footnotetext{
[...] uma vez que eles agem na natureza do ponto de vista do universo e não na teia de relações humanas, carece do caráter revelador da ação e da capacidade de produzir estórias e tornar-se histórica, caráter e capacidade que constituem juntos a própria fonte da qual brota a significância que ilumina a existência humana.
}

Esse fenômeno é manifestado pelo "aplainamento", situação em que "o dualismo da epistemologia e da ontologia se perde no monismo radical da tecnologia" (LASH, 2005, p. 44). Para essa análise, Lash (2005, p. 45) se utiliza da fenomenologia empirista de Garfinkel, para aduzir que a "reflexividade já não está separada, mas sim 'encarnada' nas atividades”. O fazer é ao mesmo tempo conhecer. Essa reflexividade tecnológica presume uma "fusão da teoria e da prática", portanto, "pensar não só é ao mesmo tempo fazer, como também é 
comunicar". Para Lash (2005, p. 46-49), as "formas tecnológicas de vida", ao serem "nãolineares", apresentam as características de (1) compressão, (2) aceleração e (3) expansão: descontinuidade. O resultado são redes que "não estão conectadas pelo laço social per se, mas sim por ligações sociotécnicas. Estão unidas por enlaces que são tanto técnicos como sociais”.

Nesse sentido, por exemplo, há o problema da profunda desigualdade que se tem estabelecido no ciberespaço ${ }^{1}$, na medida em que a Internet cria novas formas de desigualdade entre "inforricos" e "infopobres" ao estabelecer discriminações graves no acesso e utilização de informações entre o Norte e o Sul. Chama atenção o fato de haver mais linhas telefônicas na Ilha de Manhattan, Nova York, do que em toda a África, sendo que sem linhas, por óbvio, não se pode acessar a internet (RAMONET, s/d). Essa transformação conjuntural leva Lash (2005, p. 57) a dizer que "a classe social se converte em uma questão de acesso às plataformas e à condição 'no ar' das formas tecnológicas de vida [...] uma questão de acesso, não só aos meios de produção, mas também aos meios de invenção".

No âmbito da questão da biodiversidade, fala-se em "filosofia autocrática das técnicas": a domesticação total do natural e da natureza, porquanto a informação digital e genética pode converter-se em "arma contra a natureza e as culturas, todas as culturas, à exceção da cultura tecnocientífica" (SANTOS, 2005, p. 133). Tal perspectiva coaduna-se com a visão de Gilberto Dupas, quando afirma que "os vetores tecnológicos autonomizaram-se definitivamente de considerações de natureza ética, social ou de políticas públicas”. O resultado, para o autor, foi o aumento da concentração de renda e da exclusão social, o perigo de destruição do habitat humano por contaminação e a manipulação genética ameaçando o patrimônio comum da humanidade (DUPAS, 2001, p. 28-29). Nesse contex to do fenômeno da globalização, refere Altvater (1999, p. 147) que:

As estruturas de governança emergentes estão substituindo funções tradicionais do Estado, pelo menos nas áreas de política ambiental e social. Mas a importância desse tipo de governança é limitada. [...] O poder das organizações não governamentais também é limitado diante das companhias privadas. A conciliação dos direitos humanos de segunda e terceira gerações e da participação democrática com a ordem econômica mundial requer maior regulamentação política, pautada nos princípios de justiça social, participação política e sustentabilidade ambiental. O funcionamento do mercado é bom apenas para a eficiência econômica em sentido estrito - mesmo assim, quando não falha.

A assimetria Norte-Sul fica evidente sob tal enfoque, sobremaneira quando é verificado que os países "pobres" continuam sendo exportadores de recursos primários (e

\footnotetext{
${ }^{1}$ O ciberespaço foi definido por Lévy (1999, p. 17), para quem “o ciberespaço (que também chamarei de rede) é o novo meio de comunicação que surge da interconexão mundial de computadores. O termo especifica não apenas a infraestrutura material da comunicação digital, mas também o universo oceânico de informações que ela abriga, assim como os seres humanos que navegam e alimentam esse universo".
} 
agora de biodiversidade e informação genética), enquanto os países desenvolvidos exportam tecnologia. Tal situação de dependência é reproduzida internamente, nos países do Sul, demandando sua superação através do investimento em tecnologia, sempre com a preocupação do interesse público, como explica Saragoussi (2002, p. 98):

\begin{abstract}
Para criar condições de tomada de decisões autônoma e soberana sobre os recursos genéticos e o seu uso público, seriam necessários investimentos em ciência e tecnologia nos países ricos em biodiversidade. Esses investimentos deveriam ser públicos, se quisermos que os resultados das pesquisas possam beneficiar toda a população e não somente os que podem pagar pelos produtos gerados ou aqueles que são alvos de medidas sociais compensatórias. No entanto, o que temos observado é o direcionamento da pesquisa pública para atender aos interesses de empresas privadas, por meio de restrição dos recursos públicos para ciência e tecnologia e direcionamento das prioridades de pesquisa pelos investimentos das empresas privadas feitos em laboratórios públicos.
\end{abstract}

Por isso, como explica Pérez Luño (2004), a realidade em transformação exige a atualização coerente dos princípios da democracia constitucional e sua adequação aos desafios trazidos pelo progresso técnico-científico. $\mathrm{O}$ avanço da tecnologia não traz automaticamente aos novos espaços de comunicação as estruturas democráticas arduamente conquistadas na história, institucionalizadas pelos Estados e organismos internacionais. Tal avanço, então, deve estar sincronizado com as conquistas sociais, tanto no âmbito dos direitos humanos, como na seara ambiental.

Lamentavelmente, entretanto, a evolução do direito à informação tem sido marcada pela pauta neoliberal, atendendo interesses da ideologia do mercado. Os interesses e valores que "a ordem jurídico-comunitária da informação tende a proteger, preferencialmente", como afirma Gonçalves (2003, p. 132-133), "são os dos investidores, dos produtores e dos prestadores de serviço, os agentes, afinal do mercado da informação". A autora atenta, em relação ao acesso à informação, para a necessidade de "reconhecer verdadeiros direitos fundamentais dos cidadãos, nos planos social, económico e cultural, oponíveis quer aos Estados, quer aos actores económicos", insistindo na importância de "vincular juridicamente tanto os Estados, como os agentes económicos", pois a informação de "interesse público", por evidente, transcende àquela estritamente detida por órgãos públicos (GONÇALVES, 2003, p.

210).

Para o futuro, Gonçalves projeta (2003, p. 208), inclusive, uma possível necessidade de regulação de formas "mínimas" de acesso à rede, tendo em vista que provavelmente, no futuro, o acesso à informação sobre os temas publicamente relevantes (saúde, educação, meio ambiente), por todos os cidadãos, será requisito básico de participação democrática. Tal 
projeção choca-se com a realidade de condições politicamente desajustadas da globalização, onde

[...] a tomada de decisão privatizada é despolitizada, ou seja, não precisa mais da legitimação do cidadão. Os 'poderes inconstitucionais' na economia e o mundo da mídia precisam apenas apresentar um mercado atrativo para os clientes, acenar com um lucro para os acionistas e alcançar uma taxa de audiência alta; eles só têm que obedecer as regras da esfera econômica (e da mídia). Os 'poderes inconstitucionais' não estão atrelados a decisões políticas; os cidadãos, que formam uma comunidade política, são interessantes, antes de mais nada, como sujeitos econômicos, particularmente como consumidores (ALTVATER, 1999, p.119).

De toda sorte, enfrenta-se o problema em regular o uso das técnicas provenientes do progresso científico. Verifica-se que tal avanço provoca transformações potenciais, envolvendo "a própria natureza do ser, a condição de alterar a vida e o poder de mudar radicalmente as condições de produção e o meio-ambiente", pelo que urge recuperar o "controle ético" da ciência (DUPAS, 2001, p. 106-107). Aparece aqui o papel do direito, como regulador e balizamento ético da ciência e da tecnologia.

Interessante observar que, mesmo em situações em que a ciência demonstra a incerteza quanto aos malefícios de determinado produto, por exemplo, o que prevalece é o interesse econômico, que instrumentalizado pelos lobbys empresariais, força as estruturas políticas ao acatamento de suas demandas. É o caso da recente discussão, no Brasil, sobre o sinal "T", presente nos alimentos transgênicos, que visava alertar os consumidores sobre o risco do consumo ${ }^{2}$. Um projeto tramitado na Câmara dos Deputados foi aprovado, visando à retirada de tal sinal, por prejudicar a imagem dos produtos. Essa medida vai totalmente de encontro à Lei de Biossegurança $\left(n^{\circ} 11.105 / 05\right)$, que previa que todos os alimentos contendo transgênicos, para consumo humano ou animal, fossem rotulados. A partir da manobra feita pela Câmara, para "driblar" a Lei, só serão rotulados os alimentos em que for possível detectar o conteúdo transgênico por meio de análise específica, tornando a rotulagem, na prática, uma exceção (CAMARGO, 2015).

Como afirma Ost (1997, p. 100), se o direito “quiser resistir ao reducionismo biológico e às potenciais ameaças do 'biopoder', deverá deixar de se pôr a reboque da norma tecnocientífica", o que implica, para o autor, uma adoção de outra lógica: "uma lógica de participação que conduziria a uma reapropriação, pelos indivíduos, da responsabilidade pelo seu meio" (OST, 1997, p. 164). Assevera ainda o autor a necessidade de garantir o mais

\footnotetext{
${ }^{2}$ Disponível em: <http://www2.camara.leg.br/camaranoticias/noticias/CONSUMIDOR/486822-APROVADOPROJETO-QUE-DISPENSA-SIMBOLO-DA-TRANSGENIA-EM-ROTULOS-DE-PRODUTOS.html>. (Acesso em 21mar2016). Destaca-se que até a edição deste artigo, o projeto não havia sido submetido à apreciação do Senado.
} 
amplo acesso possível á informação, pois “a população deverá ser o mais amplamente possível associada à tomada das decisões". Tal debate democrático, "necessário ao alargamento da questão do meio" passa pela publicidade-transparência inerente ao espaço público, que "não deve ser confundida coma publicidade-condicionamento, típica das estratégias comerciais" (OST, 1997, p. 348).

Importante, nesse ponto, referir a Teoria da Democracia Participativa de Bonavides (2008, p. 283), para quem "o substantivo da democracia é, portanto, a participação", pois “sem a participação popular, democracia é quimera, é utopia, é ilusão, é retórica, é promessa sem arrimo na realidade, sem raiz na história, sem sentido na doutrina, sem conteúdo nas leis". Dessa forma, "a democracia participativa desloca o eixo do poder no exercício da soberania, dos corpos representativos para as correntes da cidadania [...]”, que são constituídas pelo próprio povo (BONAVIDES, 2008, p. 285).

O modelo participativo proposto por Bonavides apresenta-se como uma alternativa, sobretudo, se aliado à utilização das tecnologias de informação e de comunicação, especialmente a Internet, para a atuação transparente daqueles que detém as informações públicas e participação popular através de canais online. Essa problemática, por certo, envolve um processo lento e gradativo de evolução da democracia, aliado a melhorias na atuação governamental e maior mobilização atores sociais, também no âmbito informacional.

Pode-se dizer, assim, que as TIC's não são propulsoras unilaterais da democracia participativa no meio digital, mas sim importantes ferramentas para intervir em uma complexa reestruturação do Estado e da sociedade, envolvendo não só a apropriação das novas tecnologias, mas também a convergência de iniciativas para a consolidação do viés democrático, sobretudo, através da transparência e da garantia do direito à informação.

Como afirma Paesani (2008, p. 8), “somente uma sociedade informatizada pode ser uma sociedade democrática", pois "o grau de democracia de um sistema pode ser medido pela quantidade e qualidade da informação transmitida e pelo número de sujeitos que a ela tem acesso". Nesse sentido, para Stroppa (2010, p. 134), "a efetivação da democracia envolve a capacitação do povo para o exercício do poder que lhes pertence, o que desde logo supõe o contato com as mais diversificadas informações por meio do pluralismo informativo". A autora afirma que a informação possibilita que o povo participe do processo político durante todo o tempo e não apenas quando chamado a votar ou a se manifestar através de plebiscitos e referendos.

Fato é que nem a tecnologia, nem a participação social, por si sós, garantem mais proteção ao meio ambiente. Mas a evolução indexada da política democrática e da técnica 
podem apresentar, pelo debate coletivo, soluções sustentáveis. O primeiro, e "mínimo" passo, por evidente, é que o cidadão seja bem informado, para que possa implicar-se na vida pública. Passa-se, então, a analisar a garantia do direito à informação sob a perspectiva do Meio Ambiente.

\section{O DIREITO FUNDAMENTAL DE ACESSO À INFORMAÇÃO EM FAVOR DO MEIO AMBIENTE: A "INFORMAÇÃO AMBIENTAL"}

Uma das dimensões centrais dos direitos humanos na atualidade diz respeito à proteção do meio ambiente, vista como requisito essencial para que os cidadãos possam desfrutar de uma vida minimamente digna. Lévy (2002, p. 178) atribui, entre as funções ideais do Estado, a "governação da biosfera", pois deve "contribuir para a pilotagem da biosfera e da sua evolução em todas as suas dimensões interdependentes, de modo a assegurar à humanidade e ao seu habitáculo terrestre as condições para um desenvolvimento sustentado”.

Interessante destacar que para o autor, com a evolução técnica e cultural, a biosfera encaminha-se, progressivamente, para um estado de "tecnobiosfera", pilotada pela tal “inteligência coletiva” dos seres dotados de linguagem (homens). Lévy (2002, p. 191) não parece ver muitos problemas nessa "pilotagem" total do planeta pelo homem, inclusive reputando-a como "desejável", desde que seja "uma pilotagem consciente de uma evolução que preserve a biodiversidade natural e a qualidade da vida humana".

As "comunidades inteligentes", a "governação eletrônica", "ágoras virtuais" e etc, seriam um novo sintoma desse novo espaço de ampliação democrática e virtual onde a participação, a cooperação e o livre acesso à informação contribuiria para soluções coletivas aos mais variados problemas sociais, dentre os quais a questão ambiental. Com efeito, o autor afirma nossa crescente capacidade em avaliar os produtos no ato de consumo, pois saberemos, por meio da transparência informativa, os impactos ambientais destes. O "consumo sustentável”, nesse viés, possibilitaria um quadro onde "adquirir determinado produto em vez de outro nos permitirá orientar a máquina econômica", bem como o "boicote" aos que causam impacto negativo (LÉVY, 2002, p. 149). Propõe Lévy (2002, p. 149) uma conversão da visão do mercado, que ao invés de "ditador antidemocrático", pode ser um "instrumento de pilotagem, um vasto sistema eleitoral permanente no seio do qual todo e qualquer acto de compra representa um voto".

No entanto, como alerta Dupas, a imbricação dos espaços sociais com as técnicas, negociado continuamente no seio das contradições políticas, "requer cidadãos esclarecidos, 
vigilantes e críticos, não 'consumidores fascinados"”. Ademais, seja por "moral, responsabilidade ou prudência", é imperioso pensar em condições de uma nova hegemonia mundial, "que inclua, mas não se constranja ao capital", onde os avanços da ciência sirvam em benefício da grande maioria dos cidadãos (DUPAS, 2001, p. 85).

Por esta razão, ao longo das últimas décadas, tem havido o reconhecimento cada vez maior de que o acesso à informação sobre o meio ambiente é chave para a participação efetiva da população na governança ambiental e para o desenvolvimento sustentável. Esta questão foi abordada substantivamente pela primeira vez na Conferência das Nações Unidas sobre Meio Ambiente e Desenvolvimento, ocorrida no Rio de Janeiro, em 1992, que resultou numa série de documentos, entre eles a Agenda 21 e a Declaração do Rio sobre meio Ambiente e Desenvolvimento. Merece destaque, aqui, o princípio 10 da Declaração do Rio, segundo o qual:

\begin{abstract}
A melhor maneira de tratar as questões ambientais é assegurar a participação, no nível apropriado, de todos os cidadãos interessados. No nível nacional, cada indivíduo terá acesso adequado às informações relativas ao meio ambiente de que disponham as autoridades públicas, inclusive informações acerca de materiais e atividades perigosas em suas comunidades, bem como a oportunidade de participar dos processos decisórios. Os Estados irão facilitar e estimular a conscientização e a participação popular, colocando as informações à disposição de todos. Será proporcionado o acesso efetivo a mecanismos judiciais e administrativos, inclusive no que se refere a compensação e reparação de danos (ONU, 1992).
\end{abstract}

Por sua vez, a Agenda 21 Global, elaborada pelos países presentes na Rio-92, trata do dever dos Estados e das organizações internacionais de rever e fortalecer os sistemas e serviços de informação relacionados ao desenvolvimento sustentável nos planos local, regional, nacional e internacional:

Deve-se dar ênfase especial à transformação da informação existente em formas mais úteis para a tomada de decisões e em orientá-la para diferentes grupos de usuários. Devem-se estabelecer ou fortalecer mecanismos para converter as avaliações científicas e sócio-econômicas em informação adequada para o planejamento e a informação pública. Devem-se utilizar formatos eletrônicos e não- eletrônicos (ONU, 1992b).

$\mathrm{Na}$ mesma trilha destes acordos, em 1998 os Estados Membros da Comissão Econômica da ONU para a Europa e a União Europeia firmaram a Convenção sobre o Acesso à Informação, Participação Pública na Tomada de Decisões e Acesso à Justiça em Assuntos Ambientais (Convenção de Aarhus). Este documento reconhece que o acesso à informação é parte do direito a viver em um ambiente saudável e obriga os Estados Partes a tomarem as 
medidas jurídicas necessárias para implantar suas disposições sobre o acesso à informação ambiental.

A Convenção define informação ambiental como qualquer informação apresentada sob a forma escrita, visual, oral, eletrônica, ou outra, sobre o estado dos elementos ambientais, locais de interesse paisagístico e natural, diversidade biológica, fatores relacionados à energia, medidas administrativas, acordos, política, legislação, planos e programas ambientais, análises econômicas que afetem a tomada de decisões de caráter ambiental, o estado da saúde e condições humanas e outras condições ambientais físicas que possam ser afetadas por atividades ou medidas de interesse ambiental.

Além dos marcos normativos citados, diversos instrumentos específicos estabelecem o direito de acesso a informações relacionadas ao meio ambiente. Um deles é o Protocolo de Cartagena sobre Biossegurança para a Convenção sobre a Diversidade Biológica, o qual requer que os Estados promovam e facilitem o acesso à informação, a conscientização pública, educação e participação relacionadas com a segurança na transferência, manejo e uso de organismos geneticamente modificados.

Diante da construção desse cenário internacional em que se vislumbra a importância do acesso a informações sobre meio ambiente para a governança ambiental e participação da sociedade civil na proteção e prevenção contra riscos ambientais, destaca-se que no Brasil, além da previsão constitucional do direito de acesso à informação pública de modo abrangente, na seara ambiental vige a Lei $\mathrm{n}^{\circ} 10.650 / 2003$, que determina que órgãos e entidades integrantes do Sistema Nacional do Meio Ambiente (SISNAMA) fiquem obrigados a permitir o acesso público aos documentos, processos administrativos e expedientes que tratem de questões ambientais, bem como devem fornecer informações ambientais que estejam sob sua guarda.

Além disso, seguindo a tendência internacional e os documentos assinados pelo Brasil, em 18 de novembro de 2011 foi publicada no país a Lei de Acesso à Informação Pública (LAI) $\mathrm{n}^{\circ}$ 12.527, a qual regulamentou esse direito, impondo aos órgãos integrantes dos Poderes Públicos o dever de manter informações de interesse público em seus sites e portais, com o escopo de publicizar e garantir a transparência dos serviços ao usuário.

Essa regulamentação fortalece a ideia de máxima divulgação de informações, em detrimento do sigilo e do monopólio estatal. Justamente por ter natureza coletiva e difusa, o direito à informação assume destaque nos Estados democráticos, principalmente quando a informação diz respeito ao patrimônio existente na natureza, bem como às políticas, medidas e decisões que tenham por objeto tais recursos. Dessa forma, o direito à informação é 
relevante para a proteção do meio ambiente, tendo em vista que cidadãos cônscios acerca de questões ambientais estão mais preparados para fornecer uma opinião qualificada para demandar o Poder Público em favor da proteção e da preservação do ecossistema. Conforme já alertou a Artigo 19 (s/d, p. 3),

\begin{abstract}
A garantia do direito de acesso a informações ambientais permite à sociedade civil a participação em espaços de tomada de decisão, na elaboração e monitoramento de políticas públicas na área ambiental, direito este fundamental para a manutenção do equilíbrio e sustentabilidade dos ambientes.
\end{abstract}

Nesse sentido, a transparência e a divulgação de informações deve contribuir para a participação qualificada e comprometida dos cidadãos, conforme ressalta Graf (1998, p. 24), ao abordar especificamente o direito à informação ambiental:

\begin{abstract}
$\mathrm{O}$ direito às informações de que o Estado dispõe fundamenta-se no princípio da publicidade dos atos administrativos e na eliminação dos segredos públicos. Neste sentido, o direito à informação constitui um indicador significativo dos avanços em direção a uma democracia participativa: oponível ao Estado, comprova a adoção do princípio da publicidade dos atos administrativos; sob o ponto de vista do cidadão, é instrumento de controle social do poder e pressuposto da participação popular, na medida em que o habilita para interferir efetivamente nas decisões governamentais e, se analisado em conjunto com a liberdade de imprensa e banimento da censura, também funciona como instrumento de controle social do poder.
\end{abstract}

Essa participação da população, que pode ser materializada através de consultas e audiências públicas, por exemplo, está diretamente relacionada à garantia do direito à informação ambiental.

A informação ambiental surge, assim, como uma maneira de resgatar o homem de sua condição de alienação e passividade, concedendo-lhe um instrumento (informação) de cidadania e de participação decisória. Tornando este indivíduo apto para envolver-se ativamente na condução de processos decisórios que hão de decidir o futuro da humanidade sobre a Terra (MILARÉ, 2004, p. 343). O autor pontua, ainda, quatro formas de participação popular em matéria de Direito Ambiental: no processo legislativo (Projetos de Lei de iniciativa Popular, Referendos, etc.); participação da sociedade civil em órgãos administrativos e colegiados (v.g. CONAMA); discussão em audiências públicas na elaboração e execução de políticas ambientais; medidas judiciais (Ação Civil Pública, Ação Popular, Mandado de Segurança coletivo e Mandado de Injunção, etc.) (MILARÉ, 2004, p. 353-355). 
Portanto, evidencia-se que, na evolução que se tem observado na esfera normativa, as informações relativas ao Meio Ambiente - ou o "direito à informação ambiental", tem sido elevadas como espécie do gênero Direito à Informação, de modo que carregam o mesmo grau de fundamentabilidade, porquanto indispensáveis ao pleno exercício de toda uma gama de direitos fundamentais, dentre os quais o Meio Ambiente ecologicamente equilibrado. A partir desse aporte teórico, no próximo tópico serão analisados alguns exemplos práticos que envolvem tecnologia, informação e meio ambiente.

\section{ESTUDO DE CASOS REAIS DE (DES)INFORMAÇÃO AMBIENTAL NO BRASIL}

Apesar de todo o risco que a evolução tecnológica acarreta à natureza e às relações humanas, é possível verificar iniciativas e experiências que demonstram as possibilidades que as TIC's promovem à organização e participação de grupos e movimentos sociais. Um exemplo é a Escola de Ativismo e Mobilização para a Sustentabilidade - MAS. Esta escola oferece um curso online a fim de qualificar e aperfeiçoar a prática política dos grupos, movimentos e organizações que atuam na defesa, promoção e garantia dos direitos humanos, da democracia e da sustentabilidade.

Também existem articulações de movimentos sociais ambientalistas, como no caso da luta contra a construção da usina de Belo Monte, através do Movimento Gota D’Água que divulgou seus objetivos, concedeu informações sobre o planejamento energético, além de promover amplo debate nas mais diversas redes sociais disponíveis, sob todas as plataformas. Ainda, podem ser verificados diversos casos de ONGs de intensa atuação na causa ambiental, muitas vezes datando de muito antes do ativismo "digital", mas que tiveram suas atividades alavancadas após o aproveitamento das potencialidades das TIC's, como o Instituto Socioambiental e a Fundação SOS Mata-Atlântica.

Ainda assim, mesmo diante de um quadro amplo de proteção normativa na seara do direito à informação e ao Meio Ambiente, podem-se destacar no Brasil casos emblemáticos em relação à violação do direito de obtenção de informações de interesse ambiental.

Um desses casos refere-se justamente à construção da Usina Hidrelétrica de Belo Monte, no Estado do Pará. Neste caso, a Comissão Interamericana de Direitos Humanos requereu a paralisação das obras sob a justificativa de que o Estado brasileiro não havia respeitado o direito à informação das comunidades que seriam afetadas pela construção da usina. A Corte argumentou que a violação do direito à informação deu-se, entre outros motivos, pela não publicação do estudo de impacto ambiental em tempo suficiente para que 
pudesse ser contestado e analisado e pela ausência de tradução do texto e dos dados para a língua nativa das tribos indígenas da localizada. Essa falta de informação violou não somente o direito dos afetados de modo direito pela construção da usina, como da população de todo o país, uma vez que houve negligência na prestação do acesso à informação que era devida a população (ARTIGO 19, s/d, p. 4).

Outro caso interessante de análise é o do Sistema Cantareira e a crise ambiental em São Paulo em face da ausência de transparência das informações públicas. Tal o sistema passa por uma crítica situação em decorrência da queda contínua dos níveis de água disponíveis para fins de abastecimento. Em razão dos baixos níveis dos reservatórios, desde maio de 2014 a Companhia de Saneamento Básico do Estado de São Paulo (Sabesp) tem oferecido à população água captada abaixo dos níveis normais, o chamado volume morto, que consiste em reserva de água mais profunda do reservatório, localizada abaixo das bombas de captação, utilizada em situações emergenciais. Todavia, conforme destacado pela Organização não governamental Artigo 19 no relatório intitulado "Sistema da Cantareira e crise da água em São Paulo: a falta de transparência no acesso à informação", a queda não se deve exclusivamente à contínua falta de chuvas e revelou desencontros de informações públicas prestadas à população no estado de São Paulo.

No estudo acima referido, a Artigo 19 buscou verificar se havia falta de transparência nas informações veiculadas pelos órgãos de controle sobre a gestão da água no Sistema Cantareira e quais seriam as possíveis consequências do sigilo de informações pelas instituições governamentais sobre a gestão da água no Sistema Cantareira (ARTIGO 19, 2014, p. 6-7). Na sequência, a Artigo 19 apresentou uma revisão cronológica, desde o ano de 2003 até o desencadeamento da crise em 2014, acerca dos acontecimentos, declarações e posicionamento dos atores envolvidos na crise do Sistema Cantareira em São Paulo, evidenciando que informações de interesse público relacionadas aos direitos fundamentais de acesso à informação e de acesso à água potável, foram mantidas em sigilo pelas instituições governamentais do Estado de São Paulo, revelando o descumprimento da Lei de Acesso à Informação brasileira (Lei no 12.527, de 18 de novembro de 2011).

Assim, o governo do Estado de São Paulo nitidamente descumpriu o dever de transparência ativa ao deixar de informar aos cidadãos paulistas acerca de um problema hídrico que estava sendo objeto de enfrentamento desde o ano de 2003. Essa postura se revela extremamente gravosa na medida em que dificultou ou impossibilitou o exercício do controle social e da participação popular em questões ambientais, perante as quais "a necessidade de transparência se faz mais presente por se tratar de direitos difusos e coletivos, os quais levam 
em conta os princípios de direito à liberdade de expressão, à água e ao saneamento" (ARTIGO 19, 2014, p. 21).

Importante referir que a Política Nacional de Recursos Hídricos, de 8 de janeiro de 1997, regulamentou o artigo 21, inciso XIX da Constituição Federal ${ }^{3}$, e criou o Sistema de Informações sobre Recursos Hídricos, responsável pela "coleta, tratamento, armazenamento e recuperação de informações sobre recursos hídricos e fatores intervenientes em sua gestão", tendo como base principiológica a descentralização da obtenção e produção de dados e informações, a coordenação unificada do sistema e o acesso aos dados e informações garantido à toda a sociedade (BRASIL, 1997). Disso se extrai que antes da promulgação da lei específica para a regulamentação do acesso à informações públicas, em matéria ambiental já havia legislação que determinava a publicidade de dados e informações à sociedade, especialmente no que tange aos recursos hídricos.

A partir dessas premissas, a Artigo 19 analisou o grau de transparência no acesso à informação sobre a crise da água, tendo como base a avaliação dos sites oficiais das instituições e órgãos envolvidos com o problema da crise da água em São Paulo, utilizando critérios de acessibilidade, qualidade e compreensibilidade da informação (ARTIGO 19, 2014, p. 22). A análise dos portais demonstrou que "as informações disponibilizadas, pelas instituições e órgãos de gestão e controle, não são totalmente transparentes no que diz respeito ao acesso e disponibilização das informações sobre a Crise da Água no Sistema Cantareira", porquanto "dos onze sítios pesquisados, quatro apresentaram nenhuma transparência no acesso às informações sobre o tema, dois apresentaram baixa transparência, e os outros cinco foram classificados com nível de transparência médio". Ademais, segundo a ONG, "nenhum site pesquisado obteve índice de transparência alto de acordo com os critérios pesquisados" (ARTIGO 19, 2014, p. 29).

Percebe-se que no caso em comento houve omissão de informações através de notas e declarações oficiais, bem como a pulverização de informações em sítios eletrônicos ou publicação realizada apenas através de diários oficiais, em prejuízo ao efetivo acesso pela população. Neste viés, algumas publicações detinham caráter técnico e, por essa razão, não eram compreendidas, revelando o distanciamento existente entre os atores envolvidos na gestão hídrica do estado de São Paulo e os cidadãos. Para além disso, o paradigma da cultura de acesso, baseada na publicidade e na transparência, em detrimento do sigilo das informações, foi flagrantemente ignorado, em prejuízo daqueles que além de serem

\footnotetext{
${ }^{3}$ Art. 21. Compete à União: [...] XIX - instituir sistema nacional de gerenciamento de recursos hídricos e definir critérios de outorga de direitos de seu uso (BRASIL, 1988).
} 
consumidores do serviço de água são também cidadãos e deveriam ter assegurado o direito de exercer a cidadania e de realizar o controle social, no Estado Democrático de Direito.

Conforme a análise realizada pela Artigo 19, o Estado de São Paulo deixou de incluir os cidadãos paulistas nas discussões relacionadas à crise hídrica e à própria fragilidade enfrentada pelo Sistema Cantareira. Em pesquisa realizada pelo Datafolha no mês de agosto de 2014, 71\% da população paulista acreditava que o governo só divulga as informações sobre a crise que interessam a ele próprio (ARTIGO 19, 2014, p. 18). Todavia, não se pode olvidar que "os órgãos públicos não detêm informações eles próprios, mas atuam como guardiães do bem público" (MENDEL, 2009, p. 4), razão pela qual possuem a obrigação da gestão transparente das informações públicas. Ao fazê-lo, possibilitam a participação popular, imprescindível para garantir-se a democracia.

São Paulo, por outro lado, não só deixou de cumprir o ônus da transparência ativa, como também da passiva, quando os órgãos públicos, empresas públicas, comitês e agências reguladoras foram demandadas a fornecer informações. Consoante apontado pela ONG o período eleitoral foi utilizado pelo ente governamental para restringir "parcialmente o acesso ao conteúdo de diversos portais e canais de comunicação eletrônicos dos organismos ligados à administração pública paulista", não distinguindo publicidades institucionais e adotando rigor que extrapola o que a lei eleitoral determina, o que teve como consequência direta a restrição infundada do acesso à informação (ARTIGO 19, 2014, p. 33).

Diante de tudo isso, a crise da água em São Paulo demonstra que o acesso às informações não está fundado nos princípios da máxima divulgação e do governo aberto (ARTIGO 19, 2014, p. 34-35). Constatou-se efetivamente, que a atuação dos órgãos de gestão e controle sobre a crise da água no Sistema Cantareira não foi transparente, destacando a “dificuldade no acesso e compreensão das informações, a indisponibilidade de declarações e notas oficiais e às informações controversas apresentadas pelas instituições governamentais" (ARTIGO 19, 2014, p. 39). Houve desencontro de informações e baixo consenso entre os gestores e reguladores acerca do conteúdo dos dados repassados à população paulista, estando evidenciada a tentativa governamental de minimizar a gravidade do problema de abastecimento de água, que teve seu auge durante período eleitoral (ARTIGO 19, 2014, p. 39). Por consequência, direitos fundamentais foram violados, emergiu nesse contexto incertezas e a fragilidade democrática atinente à tomada de decisão pelo Estado de São Paulo, trazendo à tona a crise de representação.

Desde o agravamento da crise da água no Estado de São Paulo verificou-se a ocorrência de manifestações populares, bem como de iniciativas adotadas por institutos, 
organizações, dentre outros, no sentido de combater o sigilo de informações e as medidas adotadas para solucionar o problema de escassez. Dentre elas, cita-se o Instituto Brasileiro de Defesa do Consumidor criou o canal de participação online intitulado "Tô sem água" a fim de apontar e direcionar os problemas apresentados pelos consumidores aos órgãos competentes para solução. Em seu site oficial, o Instituto declarou que considera o corte de água sem a declaração por parte do estado enfatizando racionamento é ilegal pelo Código de Defesa do Consumidor e caracteriza a má prestação de serviços, bem como a quebra da continuidade dos serviços públicos essenciais, previstos nos artigos $5^{\circ}$ e $1^{\circ}$, inciso III, da Constituição Federal (IDEC, 2014).

Além disso, no site do Instituto o consumidor internauta pode participar relatando se está faltando água no bairro em que reside, informando a cidade, o bairro, o período e a frequência, ou, ainda, pressionar a Sabresp por mais informações. A campanha "Tô sem Água", desenvolvida através da Internet, se mostrou uma boa ferramenta participativa, já que após 700 relatos sobre a falta de água, o IDEC formalizou requerimento à Sobresp, com base na Lei de Acesso à Informação, e a empresa forneceu mapas da cidade de São Paulo onde supostamente há falta d'água (IDEC, 2014), representando uma atitude proativa dos consumidores na busca pelo cumprimento do dever de transparência passiva através da mobilização virtual.

A partir dessas breves considerações, é possível afirmar que apesar dos avanços tímidos em relação à efetivação do direito à informação ambiental pelo Estado, identificam-se diversas experiências de articulação e expansão de movimentos sociais engajados em causas ambientais, através da utilização das tecnologias de informação e de comunicação (TIC's), o que contribui para o fortalecimento da democracia no país.

\section{CONSIDERAÇÕES FINAIS}

Através do presente estudo foi possível perceber que o avanço tecnológico, apesar de apresentar riscos de agravar as crises, apresenta um potencial de alavancar a democracia e a proteção ambiental, sendo que o acesso à informação (latu sensu, bem como a informação ambiental) é o um requisito essencial para o empoderamento político e a participação social, visando a consecução de tais objetivos.

Nesse contexto, destaca-se a necessidade de afirmar o papel do direito, como regulador e balizamento ético da ciência e da tecnologia. Além disso, o acesso à informação sobre o meio ambiente é chave para a participação efetiva da população na governança 
ambiental e para o desenvolvimento sustentável. Destaca-se, em tal cenário, a utilização das tecnologias de informação e de comunicação (TIC's) para o acesso ao conhecimento, disseminação de conteúdos e exercício do controle social.

Todavia, também foi possível constatar que a tecnologia e a participação social não são os únicos meios para a proteção ao meio ambiente, sendo essencial a evolução indexada da política democrática e da técnica, que podem apresentar, pelo debate coletivo, soluções sustentáveis. O primeiro, e "mínimo" passo, por evidente, é que o cidadão seja bem informado, para que possa implicar-se na vida pública, inserindo demandas, provocando o Poder Público a apresentar respostas e exercendo assim o controle social, também em matéria ambiental.

Como visto, a tomada de decisão privatizada é despolitizada, de modo que a população deve ser o mais amplamente possível associada aos processos decisórios, por todas as vias possíveis, a fim de evitar-se consequências graves decorrentes da falta de acesso à informação à população, conforme ocorreu no caso do Sistema da Cantareira e da crise da água no estado de São Paulo.

Diante desse contexto, se mostra imprescindível, para o aprofundamento de uma democracia verdadeiramente legítima, a consolidação de uma lógica de participação, até mesmo visando uma "reapropriação" pelos cidadãos, da responsabilidade pelo meio ecologicamente saudável. A informação ambiental, neste sentido, aparece como um requisito fundamental para a realização da perspectiva de resgatar os indivíduos e coletivos de uma condição passiva e assujeitada, atribuindo-lhes um instrumento (a informação) de cidadania e de participação nos processos decisórios.

\section{REFERÊNCIAS}

AGENDA 21. Conferência das Nações Unidas sobre Meio Ambiente e Desenvolvimento (Rio-92). Disponível em: <http://www.onu.org.br/rio20/img/2012/01/agenda21.pdf>. Acesso em: 21 mar. 2016.

ALTVATER, Elmar. Os desafios da globalização e da crise ecológica para o discurso da democracia e dos direitos humanos In: HELLER, Agnes [et al]. A crise dos paradigmas sociais e os desafios para o século XXI. Rio de Janeiro: Contraponto, 1999.

AMS. Escola de Ativismo e Mobilização para Sustentabilidade. [.s.d]. Disponível em: <http://www.eativismo.org/>. Acesso em: 21 mar. 2016.

ARENDT, Hannah. A condição humana. Tradução: Roberto Raposo. 11 ed. Rio de Janeiro: Forense Universitária, 2010. 
ARTIGO 19. Acesso à informação ambiental. Disponível em: <http://artigo19.org/doc/CARTILHAAMBIENTALARTIGO19.pdf>. Acesso em: 21 mar. 2016.

- Sistema da Cantareira e crise da água em São Paulo: a falta de transparência no acesso à informação. Artigo 19: São Paulo, 2014. Disponível em: $<$ http://artigo19.org/blog/relatorio-sistema-cantareira-e-a-crise-da-agua-em-sao-paulo-a-faltade-transparencia-no-acesso-a-informacao/ > . Acesso em: 21 mar. 2016.

BONAVIDES, Paulo. Teoria constitucional da Democracia Participativa (Por um Direito Constitucional de luta e resistência, por uma Nova Hermenêutica, por uma repolitização da legitimidade). 3. ed. São Paulo: Malheiros Editores, 2008.

CAMARGO, Flávia. Manobra dos deputados pretende esconder do consumidor se o alimento contém transgênico. In: Instituto Socioambiental. Disponível em: $<\mathrm{http}$ ///www.socioambiental.org/pt-br/blog/blog-do-ppds/manobra-dos-deputados-pretendeesconder-do-consumidor-se-o-alimento-contem-transgenico>. Acesso em: 21 mar. 2016.

DECLARAÇÃO DO RIO DE JANEIRO SOBRE MEIO AMBIENTE E DESENVOLVIMENTO. Conferência das Nações Unidas sobre Meio Ambiente e Desenvolvimento (Rio-92).

Disponível em: <http://www.onu.org.br/rio20/img/2012/01/rio92.pdf>. Acesso em: 21 mar. 2016.

DUPAS, Gilberto. Ética e poder na sociedade da informação: de como a autonomia das novas tecnologias obriga a rever o mito do progresso. 2. ed. rev. e ampl. São Paulo: UNESP, 2001.

GONÇALVES, Maria Eduarda. Direito da informação: novos direitos e formas de regulação na sociedade de informação. Coimbra: Almedina, 2003.

GOTA D’ÁGUA - MOVIMENTO GOTA D’AGUA. [s.d.]. Disponível em: <http://www.movimentogotadagua.com.br/>. Acesso em: 21 mar. 2016.

GRAF, Ana Cláudia Bento. O direito à informação ambiental. Direito Ambiental em Evolução. Curitiba: Juruá, 1998.

INSTITUTO BRASILEIRO DE DEFESA DO CONSUMIDOR. Especial Tô Sem Água. Disponível em: <http://www.idec.org.br/especial/to-sem-agua>. Acesso em: 21 mar. 2016.

INSTITUTO SOCIOAMBIENTAL. (s/d). Disponível em: <http://www.socioambiental.org/pt-br>. Acesso em: 21 mar. 2016.

LASH, Scott. Crítica de lainformación. 1. ed. Buenos Aires: Amorrortu, 2005.

LEVY, Pierre. Cibercultura. São Paulo: Editora 34, 1999.

Ciberdemocracia. Lisboa: Instituto Piaget, 2002. 
MENDEL, Toby. Liberdade de informação: um estudo de direito comparado. 2. ed. Brasília: UNESCO, 2009.

MILARÉ, Édis. Direito do ambiente. 3. ed. São Paulo: Revista dos Tribunais, 2004.

ORGANIZAÇÃO DAS NAÇÕES UNIDAS (ONU). Assembleia Geral, de 28 de julho de 2010. Disponível em: <http://www.onwa.ca/upload/documents/un-water-as-a-humanright.pdf $>$. Acesso em: 21 mar. 2016.

- Relatório do Relator Especial: Promotion and protection of the right to freedom of opinion and expression, Doc. da ONU, de 28 janeiro de 1998, § 14.

. Declaração do Rio sobre Meio

Ambiente e Desenvolvimento. Publicada em 1992. Disponível em: <http://www.onu.org.br/rio20/img/2012/01/rio92.pdf>. Acesso em: 21 mar. 2016.

Disponível em:

Agenda 21 Global. Publicada em 1992.

<http://www.meioambiente.pr.gov.br/arquivos/File/agenda21/Agenda_21_Global_Integra.pdf

>. Acesso em: 21 mar. 2016.

OST, François. A Natureza à margem da lei: a ecologia à prova do direito. Traduzido por Joana Chaves. Lisboa: Instituto PIAGET, 1997.

PÉREZ LUÑO, Antonio-Enrique. Ciberciudadaní@ o ciudadaní@.com? Barcelona: Editorial Gedisa S.A., 2004.

RAMONET, Ignacio. ¡Nos hanrobado una esperanza! S/d. Disponível em: $<\mathrm{http}$ ///pendientedemigracion.ucm.es/info/uepei/noshanrobado.html>. Acesso em: 21 mar. 2016.

SANTOS, Laymert Garcia dos Santos. Quando o conhecimento tecnocientífico se torna predação high-tech: recursos genéticos e conhecimento tradicional no Brasil. In: SOUSA SANTOS, Boaventura de (Org.). Semear outras soluções: os caminhos da biodiversidade e dos conhecimentos rivais. Rio de Janeiro: Civilização Brasileira, 2005.

SARAGOUSSI, Muriel. Direito de acesso à proteção e uso da biodiversidade. In: BORN, Rubens Harry (coord.). Diálogos entre as esferas global e local: contribuições de organizações não-governamentais e movimentos sociais brasileiros para a sustentabilidade, equidade e democracia planetária. São Paulo: Editora Fundação Peirópolis, 2002.

SOS MATA ATLÂNTICA. Disponível em: <https://www.sosma.org.br/>. Acesso em: 21 mar. 2016. 